\author{
EMILIE CARREÓN BLAINE \\ INSTITUTO DE INVESTIGACIONES ESTÉTICAS, UNAM
}

\title{
Barbie en Palenque, o la manufactura de lo intangible
}

\author{
Escondida por los rincones, \\ temerosa de que alguien la vea, \\ platicaba con los ratones \\ la pobre muñeca fea.
}

CRI-Cri. ${ }^{\mathrm{I}}$

B ARBIE ES UNA MUÑECA INQUIETANTEMENTE familiar para algunos, símbolo de un ideal femenino que ha invadido la cultura popular. Producto del capitalismo consumista occidental en un mundo multicultural en expansión y fusión, se ha convertido en un icono cultural ficticio. ${ }^{2} \mathrm{Ha}$ sido materia prima, tema y musa de obras de arte moderno y contemporáneo des

I. Francisco Gabilondo Soler, "La muñeca fea". Quiero agradecer a Deborah Dorotinsky y a los miembros del Taller de Cultura Visual y Arte: Diálogos Metodológicos desde la Imagen, del Posgrado en Historia del Arte, Universidad Nacional Autónoma de México (UnAM), sus comentarios a la primera versión de este texto. Asimismo a Mari-Areti Hers por sus observaciones en el marco de las Jornadas del Instituto de Investigaciones Estéticas de la UNAM. Finalmente a Myriam Peignist y Miguel de la Torre por la información del fenómeno Barbie en Francia, Alemania y México, respectivamente, así como a los dictaminadores por sus relevantes comentarios y observaciones. Dedico este artículo a Sally y Sabina.

2. Como Barbie, Superman, Batman y Miss Piggy, personajes de ficción, son iconos culturales que solamente existen en nuestra imaginación, a diferencia del Che Guevara, Michael Jackson y Madonna, por ejemplo, iconos culturales forjados sobre personas reales. Mary G. Lord, Forever Barbie: The Unauthorized Biography of a Real Doll, Nueva York, Walker, 2004, pp. 6-7 y 73; Allan Lazar et al., The IOI Most Influential People Who Never Lived, Nueva York, 
de finales de los años setenta, ${ }^{3}$ y también es señalada como una obra de arte. ${ }^{4} \mathrm{Ha}$ bla de la imagen corporal y la manera como niñas y mujeres conciben su cuerpo, de sexismo y estereotipos de feminidad, así como de estándares y concepciones de belleza occidental europea. Como personaje de la cultura popular estadounidense, ha modelado la sociedad, cambiando comportamientos y actitudes, e incluso el rumbo de la historia, debido a su excepcional mediatización, que mayormente se ha discutido para ejemplificar temas de género, identidad sexual y consumismo.5 Otros han analizado las muñecas Barbie étnicas e internacionales, es decir, muñecas no blancas, al realizar estudios ligados a temas de etnicidad, identidad cultural y racial. Su interés reside principalmente en una serie de muñecas que representan a mujeres afroamericanas y en aquellas que están y se ven racial o étnicamente marcadas y determinadas como nativas americanas. ${ }^{6}$

Harper, 2006; Kim Toffoletti, Cyborgs and Barbie Dolls: Feminism, Popular Culture and the Posthuman Body, Nueva York, I.B. Tauris, 2007, pp. 57-80.

3. Una vez que la primera generación de sus consumidores maduró, se crearon las primeras obras de arte, autorizadas y no, de la muñeca; Lord, op. cit., cap. I3, "Barbie Out of Control", pp. 252-272, adelanta una reseña de las obras, entre las cuales destacan las imágenes de Barbie realizadas por Andy Warhol y las que fabricó Reginald Case con las muñecas. También cabe mencionar las exposiciones que se han llevado a cabo en museos de arte y galerías, como la polémica exposición de 1995 "Art, Design and Barbie: The Evolution of a Cultural Icon" en el World Financial Center Liberty Street Gallery de Nueva York, que reunió muchas obras de artistas inspiradas en la muñeca y presentó una historia de su creación y evolución. La exposición "Barbie 50 años. Historia, moda y diseño" que se montó en el Museo Franz Mayer en 2009 en la ciudad de México, también merece aquí nuestra mención.

4. Barbie ha sido patentada como una "obra de arte". Para algunos, la muñeca es la esencia del arte para las masas. Véanse por ejemplo Lord, op. cit., p. 73, y Kristin Noelle Weissman, The Icon, The Image, The Ideal, Estados Unidos, Universal Publishers/Upublish.com, I999, pp. 88, aunque, a diferencia de las reproducciones mecanizadas de una obra, la muñeca no es una mera reproducción. Como la fotografía impresa de un negativo, del cual es posible sacar gran cantidad de "originales", cada Barbie puede ser concebida como una "obra de arte". Cada muñeca contiene el aura del original y está al alcance de todos. Véase Walter Benjamin, "La obra de arte en la época de su reproductibilidad técnica", en Obras, Rolf Tiedemann y Hermann Schweppenhäuser (eds.), Madrid, Abada, 2008, lib. I, vol. 2, pp. I2-I9.

5. Véanse los estudios de Stephen C. Dubin, "Who's that Girl? The World of Barbie Deconstructed", en The Barbie Chronicles: A Real Doll Turns 40, Nueva York, Simon \& Schuster/Touchstone, 1999, pp. 19-38, y Stephen C. Dubin, Displays of Power: Controversy in the American Museum from Enola Gay to Sensation, Nueva York/Londres, New York University Press, 2000.

6. Mary F. Rogers, en su obra Barbie Culture, Londres, SAGE, 1999, en el apartado "White Skin Barbie", pp. 47-57, aborda temas ligados a las Barbie étnica e internacionales. Véanse Lord, 
Por mi parte, buscaré enriquecer la discusión al explorar la muñeca Barbie Princesa del México antiguo desde la perspectiva de la antropología de la imagen, entendida como el estudio de la representación visual donde el ser humano es el generador de imágenes en áreas como la producción y la recepción de los medios masivos de comunicación.7 No analizaré cada componente de la muñeca: contexto, embalaje, vestimenta, joyas, postura, entre otros. Describiré determinados aspectos de su creación, principalmente aquéllos ligados a la manera en la cual ha representado diferentes dimensiones de la realidad mexicana, es decir, el México precolombino y el moderno, así como el mecanismo del proceso de asociaciones que se generan entre sus creadores y sus poseedores. La muñeca habla de las realidades, ideas y actitudes nacionales que han cruzado las fronteras entre países, dirigidas hacia los antiguos y los actuales pueblos indígenas, que se desarrollaron fundadas en viejos prejuicios forjados a lo largo de varios siglos, una vez que el imaginario del Occidente enfrentó a los antiguos habitantes del continente americano.

Mostraré cómo las imágenes codificadas de antigüedades precolombinas, que poseían determinado significado e importancia, fueron traducidas para adaptarse e insertarse dentro de modernas concepciones de mercadotecnia, hasta rehabilitar y eventualmente obliterar su significado original, ${ }^{8}$ aunque hay elementos que logran trascender. Examinaré la forma en que, en distintos grados y con consecuencias diferentes, determinados fragmentos de este pasado se incorporaron a una mezcla de añadiduras, para insertarse en la cultura

op. cit., pp. 62 y I08-I09 y el capítulo 8, "Barbie Like Me”, pp. I58-I78, donde se refiere al tema de la representación de razas en muñecas. Por su parte, Michael Augustyniak analiza varias ediciones de la Barbie hispana así como a Teresa, la amiga hispánica de Barbie, en "Hispanic Barbie and Ken Dolls", en Barbie Bazaar, op.cit., vol. 8 (I), pp. 40-43; “Totally Teresa”, en Barbie Bazaar, op.cit., vol. 8 (2), pp. 40-42. Véanse también Weissman, op. cit., pp. 66-72 y 86-89, y Kristin Riddick, "Barbie: The Image of Us All”, en http://xroads.virginia.edu/ CLASS/barbie/ barb.html; consultado el I2 de abril de 20Io, así como Cornel Pewewardy, "The Barbie Doll Pocahontas", en Rethinking Columbus: The Next 500 years, Milwaukee, Rethinking Schools, I998, p. 6I, quien estudia de qué manera se conciben las imágenes de los indios americanos y se enfoca en la imagen de la princesa Pocahontas, en cómo se representa en el cine para nińos y se crean imágenes negativas de los indios de Norteamérica.

7. Hans Belting, Pour une Anthropologie des images, París, Gallimard, 2004, pp. 65-76.

8. Su destrucción simbólica, ligada a la desacralización de su contenido original, es decir ancestral, vinculado al poder y lo sagrado, empieza cuando se incorpora a nuevas necesidades simbólicas y se convierte en un juguete, en tanto su destrucción física toma lugar una vez que éste es jugado, reconfigurado y descartado. 
popular a manera de una individualización basada en nociones repetidas a lo largo de los siglos, en la cual las características propias de mujeres de diferentes culturas del continente americano se mezclan, reorganizan y readecúan en nuevas configuraciones. Asimismo, demostraré el modo como la muñeca Barbie participa en la formación de nuevas alegorías, al recoger algunas características de los prototipos de los habitantes del continente americano que se desarrollaron en el siglo XVI. A partir de su estudio, mostraré cómo se repiten las primeras alegorías de las partes del mundo — donde continentes, países y habitantes están representados por las mujeres vestidas en trajes y llevando accesorios que les designan- a la vez que se crean nuevas.

\section{¿Quién es Barbie?}

Barbie principió en la Feria del Juguete de Nueva York de 1959.9 Fue concebida por Ruth Handler, inspirada en una muñeca llamada Bild Lilli. ${ }^{\text {IO }}$ La leyenda cuenta que en un viaje a Alemania en 1956, la entonces vicepresidenta de Juguetes Mattel compró tres ejemplares de Lilli, una muñeca concebida originalmente como juguete para alimentar la fantasía de los caballeros; una vez de regreso a los Estados Unidos, Handler la transformó en una muñeca para que las nińas, como su hija Bárbara, jugaran, en cuyo honor la nombró Barbie.

9. http://es.wikipedia.org/wiki/Barbie; http://es.wikipedia.org/wiki/Ruth-Handler. También véanse Lord, $o p$. cit., cap. 2, "A Toy is Born", pp. I8-43; Rogers, op. cit., pp. 86-1 I , y Julieta García González, "Malos pasos en Alemania. 40 años de Barbie", Letras Libres, México, abril de I999, http://www.letraslibres.com/revista/letrillas/malos-pasos-en-alemania40-anos-de-barbie.

Io. La muñeca se basaba en un personaje de una tira cómica que aparecía en el diario Bild-Zeitung, y quizá debido a sus orígenes germanos los estudiosos alemanes también han tocado temas ligados a Barbie, prueba de la extensión del poder icónico de la muñeca. Véase Elke Brüns, "Barbie: Ein Bild wird Körper. Idealfunktion, Körperbild und Hassfigur im kulturellen Imaginären/Zum Film: Small Soldiers", en Ulrike Landfester (ed.), Schrift, Bild und Körper, Bielefeld, Aisthesis-Verlag, 2002, pp. I23-I 42, así como varios estudios de la obra colectiva editada por Wolfram Metzger, 40 Jahre Barbie-World: Vom deutschen Fräuleinwunder zum Kultobjekt in aller Welt (Jubiläums-Edition zur Austellung des badischen Landesmuseums in Schloss Bruchsal vom I3. Dezember 1998 bis 30. Mai 1999), Karlsruhe, INFO Verlagsgesellschaft, 1998; Bazon Brock, "Zeist und Geist Barbie: Künstler und Designergestalten für und um Barbie”, en Tasse oder Untertasse: örtlich, zeitlich, persönlich. Künstler und Gestalter der Bergischen Universität Wuppertal, Uwe Loesch (ed.), Wuppertal, Von der Heydt-Museum, 1994, pp. IO-I3. 
La primera Barbie en salir al mercado vestía un traje de baño de rayas en blanco y negro; con el tiempo se le creó una línea de ropa y accesorios y una serie de artículos como coche, lancha, motocicleta, alberca, bicicleta. Tiene vestido de novia, ropa de día y de noche, además de una serie de trajes adecuados a sus aficiones y profesiones. ${ }^{\text {II }}$ Barbie ha encarnado a varios personajes y ejercido más de 120 carreras. Empezó como modelo, maniquí de moda..., pero ha sido igualmente médico, maestra, enfermera, candidata a la presidencia, soldado, medallista olímpica, veterinaria, piloto de avión y azafata, e incluso piloto de Nascar, en un esfuerzo por presentarla como un ideal y para — en palabras de la portavoz de Mattel_ "mostrar que en su vida la mujer puede tomar una variedad de papeles" acordes con los acontecimientos actuales. ${ }^{\mathrm{I} 2}$ En I965, Barbie tomó el papel de astronauta y entre las nuevas profesiones que ejercería a partir de 2010 se incluyen las de ingeniera informática y reportera de televisión. ${ }^{13}$

\section{Detrás de la concepción de la Barbie Princesa del México antiguo}

Las muñecas Barbie y la gama de accesorios que poseen expresan los valores y las creencias de sus consumidores. Tempranamente, como reflejo de nuestra época y sus sucesos, Mattel concibió las primeras muñecas afroamericanas e hispanas para responder a argumentos ligados a la equidad racial y a otros importantes movimientos sociales. ${ }^{14}$ La muñeca Francie data de 1967, Christie de 1968 y la "Black” Barbie de I980. Estas muñecas tienen la piel oscura, aunque facciones blancas, y no es sino hasta 2009 cuando Mattel lanza al mercado una representación más verídica de la mujer afroamericana. En cuanto

II. Todas las imágenes de Barbie a las cuales me refiero en el texto se pueden ver en www. barbiecollector.com. Para facilitar la búsqueda se incluye el número de serie de la muñeca.

I2. Lord, op. cit., pp. I27-I 28; http://toynewsi.com/news.php?catid=I82 \&itemid=I4965; consultado el 5 de diciembre de 2012.

I3. "Barbie, nuevas profesiones", Excélsior, I4 de febrero de 2010, sección "Función”, p. 7; Tania Cacique, “QQué bárbara!”, Reforma, 7 de marzo de 2009, sección “Gente chiquita”, p. 6. En México, Barbie ha hecho de manera encubierta el papel de Frida Kahlo; véase, por ejemplo, http://www.youtube.com/watch?v=_H5ABZbZ5ko.

I4. Como indica Lord, op. cit., pp. 7 y I30, Barbie ha conformado tanto como respondido a las demandas del mercado; o sea, su concepción, en parte, fue gestada por la sociedad pero cuidadosamente cultivada por Mattel al compás de la época. 
a Teresa, la amiga hispana de Barbie, es una muñeca que data de 1988, y para I996 ya se había presentado en 2 I versiones. ${ }^{\text {I5 }}$

Con el tiempo, en su intento por traspasar las barreras culturales, étnicas y raciales en el interior del mundo de Barbie y ampliar su mercado afroamericano e hispano, Mattel creó y produjo varias muñecas con el fin de tener acceso al poder adquisitivo de ambos segmentos de la población, ${ }^{16}$ disposiciones de mercadotecnia que presagiaron la creación y llegada de la Barbie Princesa del México antiguo al mercado de juguetes. ${ }^{17}$

\section{Muñecas del mundo}

Teresa, la Barbie hispana y las ediciones de la Barbie afroamericana son muy diferentes a las muñecas que pertenecen a la colección Muñecas del Mundo, en la cual mujeres de diversas culturas y países son representadas, incluyendo a la Barbie Princesa del México antiguo. Entender la diferencia entre estas nociones: Barbie étnica y Barbie internacional es fundamental para mi argumento. En el primer caso estamos ante muńecas que representan a grupos minoritarios - hispanos y negros — integrados a la cultura estadounidense; en el segundo, nos enfrentamos a muñecas internacionales que representan naciones. Asimismo, es relevante considerar que, como virtualmente todas las muñecas fuera de esta colección son de piel blanca y las más distribuidas y vendidas, ${ }^{18}$

I5. Augustyniak, op. cit., pp. 40-43.

I6. Riddick, op. cit.

I7. Determinar los referentes directos que influyeron a Ruth Handler y más adelante a Mattel es imposible, aunque la transnacional asegura que en la creación de la colección de las muñecas se sujeta a técnicas de investigación complejas en las cuales incorporan especialistas para garantizar la autenticidad. Véase Lord, op. cit., p. I77. No obstante, es evidente que la creación de esta muñeca vestida en un traje típico, en este caso de azteca, se vincula con el proceso de apropiación, transformación y representación de la indumentaria y las costumbres de la población americana, el cual se inicia en el siglo XVI - incluso con las tempranas representaciones de hombres y mujeres, como las de Hans Burgkmair, Hans Staden, Christoph Weiditz y André Thevet y las de los talleres de Theodore De Bry- y perdura hasta comienzos del xix. Recordemos, por ejemplo, las pinturas de castas y el costumbrismo mexicano decimonónico, así como los movimientos nacionalistas posrevolucionarios que crearon determinados tipos mexicanos cuyas características se reformularon a lo largo del tiempo para finalmente ser exportadas y en parte tomadas por las transnacionales al crear sus muñecas.

I8. Rogers, op. cit., pp. 47-53. Según Lord, op. cit., p. I76, las ediciones de Barbie negra e hispana son incluyentes, pues hacen de los consumidores negros e hispanos partícipes del sueńo 
la colección Muñecas del Mundo ha sido presentada como trascendental por Mattel. Recoge la misión que se impuso desde sus inicios: inspirar y acoger a las niñas de todos los ámbitos sociales, etnias, culturas y edades a quienes representa Barbie con muñecas de más de 50 nacionalidades, como ha expresado Stephanie Cota, vicepresidenta de mercadotecnia Barbie. ${ }^{19}$

La visión es uno de los factores primordiales detrás de la creación de $\mathrm{Mu}$ ñecas del Mundo, un concepto que se inició en 1980. Las primeras muñecas de esta serie fueron las representantes de las grandes naciones de Europa, y pronto se concibieron muñecas que encarnan a otras culturas, regiones y países. En 1986 Mattel presentó la primera edición de la Barbie Perú y tres años más tarde (1989) emitió la primera edición de la Barbie México. ${ }^{20}$

\section{Princesas, como en los cuentos de hadas...}

A primera vista se puede pensar que la Barbie Princesa del México antiguo, tema central de este estudio, es parte de la estrategia de mercadotecnia de la colección Muñecas del Mundo. Sin embargo, como la Barbie Princesa del México antiguo pertenece a una subserie de la colección Princesas del Mundo, es evidente que estamos ante un híbrido, es decir, la mezcla de dos conceptos dinámicos de comercialización, para conjuntar la visión de la colección Muñecas del Mundo con la de la colección Princesa Cuento de Hadas. Ésta se origina en 1995, cuando Barbie es Rapunzel, y continúa a lo largo de los ańos noventa con Barbie como Cenicienta, Bella Durmiente y Blanca Nieves.

Esta última colección es una de las propuestas más novedosas de Mattel. En sus reportes de accionistas explica que las muñecas Barbie más populares son princesas o parecen princesas, y mi supuesto es que, al conjugar esta estrategia con la de la colección Muñecas del Mundo, desembocó en la colección Princesas del Mundo, conformada por muñecas que permiten a las niñas

americano como lo concibe Mattel; al mismo tiempo, puntualiza que la colección Muñecas del Mundo, en la cual se representan mujeres de otras culturas y países, es excluyente debido a los errores y caracterizaciones estereotipadas de determinado grupo que así se propagan.

19. Stephanie Cota, http://www.childrensmuseum.org/barbie-the-fashion-experience-toreturn-for-an-encore y http://toynewsi.com/news.php?catid=I82 \&itemid=I 4965; consultados el 5 de diciembre de 2012.

20. La primera Barbie negra de esta colección, la Barbie africana que representa a Nigeria, se dio a conocer dos años más tarde. 
“¡Vivir el cuento de hadas!”, en tanto sus creadores anuncian: "En el mundo antiguo y en tiempos modernos, las princesas siempre han sido el retrato de la gracia y el encanto". ${ }^{21}$

Si bien es imposible determinar en qué medida el concepto de la Barbie Princesa del México antiguo deriva de la combinación de estas dos cultivadas estrategias de mercadotecnia, entenderla como producto de la necesidad de Mattel por mostrar integración social —acercamiento que al parecer se inicia cuando son concebidas las primeras Barbies hispanas y afroamericanassería simplificar las cosas. Sensiblemente, la Barbie Princesa del México antiguo, editada en 2004, es reflejo de una definida estrategia de mercadotecnia, y por tanto del interés por comercializar un producto novedoso. Pero si se analizan los motivos que rodean la comercialización de esta muñeca surgen otros problemas. Su configuración es mucho más compleja, pues reúne historias de un mundo lejano, el precolombino, con arquetipos románticos del Occidente, como demostraré analizando los textos y las imágenes que cubren el estuche de la muñeca.

\section{La Princesa del México antiguo}

La muñeca Barbie Princesa del México antiguo,

inspirada en la cultura azteca [...] lleva un vestido de algodón brillantemente impreso con un intricado diseño. Su "poncho" está decorado por un fleco rojo de algodón. Plumas de tonalidades rojas y turquesa decoran el tocado, inspirado en la época [el México antiguo]. Brazaletes de oro, un collar, abanico y ahorcas y zapatos de piel (sintética) completan este traje. ${ }^{22}$

2I. "From ancient worlds to modern times, princesses have long been the picture of enchantment and grace", http://www.barbiecollector.com/collection/dolls-word-princess-collection; páginaconsultadael 23 demarzo de20Io. Tambiénvéasehttp:/www.time.com/time/arts/article /0,8599,I947 I I 4, oo.html; htt://www.time.com/time/magazine/article/o,917 I, 2 I30393,00. html; consultado el 6 de diciembre de 20I2. Evidentemente la estrategia habla de un fenómeno peculiar estadounidense, promotor de un ideal femenino que le permite a Barbie participar de modas y eventos de la actualidad como señala Weissman, op. cit., p. 98.

22. Tarjeta informativa: Princess of Ancient Mexico ${ }^{\mathrm{TM}}$ Barbie, 2004, Collection Dolls of the World-The Princess Collection, Product Code: C2203. 
El examen de este breve texto inscrito por Mattel, donde se describe la indumentaria de la princesa, y un análisis visual de la muńeca misma dan a conocer su vestimenta y otros elementos de su atuendo. Aprendemos que viste cactli, sandalias, unas naguas o falda, cueitl, y un quechquémitl, prendas con diseños de rombos y recuadros que caracterizan las ropas de los gobernantes del México antiguo. ${ }^{23} \mathrm{El}$ "abanico" que carga aquí es un utensilio inútil, pues está confeccionado de oro y no de plumas, y el tocado, también de oro, reúne una serie de formas a manera de grecas y pirámides escalonadas, al parecer sustraídas y abstraídas de un repertorio teotihuacano. Respecto a las joyas de la princesa, observamos que las pulseras y el collar son de oro, y el pendiente en forma de chimalli o escudo, así como las demás piezas que lleva, incorporan diseños propios del estilo de los antiguos orfebres mixtecos, los cuales en conjunto tienen reminiscencias de algunos ejemplos de oro arqueológico localizados en la tumba 7 de Monte Albán. ${ }^{24}$ Como lo acabo de ejemplificar, es posible encontrar los modelos de cada elemento de esta muñeca. Sin embargo, decidí no profundizar más en este aspecto y mejor opté por analizar los textos y las imágenes inscritos en el embalaje de la muñeca. En el reverso de la caja está escrito:

Desde aproximadamente I 428 hasta I 52 I, gobernó el pueblo azteca. Sus tierras se extendían desde el Golfo de México hacia el centro de México y hacia el sur hasta llegar a Guatemala. Una chica bonita con largo y oscuro cabello y ojos marrón profundo vive en el palacio real en la capital de la ciudad de Tenochtitlán. Ella es la hija del huey tlatoani, que significa gran señor o gran orador. Él es el jefe supremo del imperio azteca y se cree que es divino. Desde su ventana, ve muchos edificios y un enorme templo. Hay tantos canales aquí, que los europeos llaman a su ciudad la Venecia del Nuevo Mundo. Como todas las personas nobles, su ropa está hecha de algodón de colores brillantes. Sus decoraciones están hechas de oro y plumas.

23. Por lo general, la mujer viste una especie de falda o enredo que se sujeta a la cintura con una faja y una camisa llamada huipil, aunque también suele cubrir su torso con otra prenda de forma romboidal conocida como quechquémitl. Patricia Anawalt, Indian Clothing Before Cortes. Mesoamerican Costumes from the Codices, Norman, Oklahoma/Londres, University of Oklahoma Press, 1981, pp. 33-37. El quechquémitl es una prenda característica de las diosas de la fertilidad mexica. También véase Códice Magliabechiano, Elizabeth Boone (ed.), Berkeley, University of California Press, I983, f. 58r; Códice Borbónico, Francisco del Paso y Troncoso y Theodore Hamy (eds.), México, Siglo XXI, 1985, lám. 31; Códice Ixtlilxóchitl, Joseph Anders (ed.), Graz, Akademische Druck-und Verlagsanstalt, 1976, lám. Io8r.

24. Alfonso Caso, La tumba 7 de Monte Albán es mixteca, México, Imprenta Mundial, I932. 
Las plumas más preciadas de todas son las verde iridiscente de un ave que se llama quetzal. Hay muchas cosas que hacer en el reino azteca. A la nińa le encanta caminar en el campo verde exuberante, donde viven muchos animales hermosos, incluyendo jaguares, colibríes, águilas y llamas. A menudo lleva a su compañero favorito —su mascota, un perro que es muy manso y amistoso. A veces ella prefiere permanecer en el Palacio. Un pasatiempo favorito es jugar patolli, un juego de mesa similar al backgammon. A menudo, mira a otros jugar un juego de pelota, llamado ulama. En este juego, la cancha representa el mundo, y la bola representaba la luna y el sol. Este deporte era muy rudo y lo jugaban los hombres. ${ }^{25}$

Si bien este texto da a conocer las actividades de Barbie como princesa del México antiguo, cabe señalar que dentro de la caja, fungiendo como escenario principal de la muńeca, se encuentra representado un panorama que la coloca en el interior del patio A del palacio de Palenque, en Chiapas. Sin embargo, las dos viñetas de la parte posterior de la caja contradicen lo anterior en tanto ilustran las palabras asentadas de manera elocuente y colocan a la princesa en Tenochtitlán, que es ahora la ciudad de México.

Comprobamos que la representación escrita y la representación visual en la caja no coinciden; se complementan para conformar un texto cultural discrepante que contextualiza a la muñeca en algún lugar del México antiguo. En una de las imágenes vemos a la princesa enjoyada y engalanada en ropas de muchos colores y con un vistoso tocado. Custodiada por su dama de compañía, ${ }^{26}$ quien viste de manera sencilla, de blanco, se pasea frente a lo que pareciera ser la escalinata del palacio de Quetzalpapálotl en Teotihuacán, aunque la gran pirámide al fondo de esta pintoresca escena, por el templo doble situado en su cima, bien podría representar el Templo Mayor de Tenochtitlán. ¿Acaso se dirigen a ver el juego de pelota? - descrito como un deporte, muy a la manera de una gesta medieval entre caballeros_-, o, se preguntaría una niña al pasar el tiempo con esta muñeca, ¿van al palacio a jugar el patolli? —un juego ancestral mesoamericano que en este caso se equipara a un juego de mesa, el backgammon, de origen persa y practicado en las cortes europeas.

25. Princess of Ancient Mexico ${ }^{\mathrm{TM}}$ Barbie, 2004, Collection Dolls of the World-The Princess Collection, Product Code: $\mathrm{C} 2203$.

26. Las posturas y la interacción entre la Barbie Princesa Azteca y los personajes que la acompañan también merecen comentario. En este caso, la dama de compañía es la que carga el bulto, mientras dirige la mirada hacia la princesa. En otros términos, toda la atención está situada en ella; la composición en el centro y todos los ejes desembocan en la princesa. 
No es éste el lugar para determinar la necesidad o la utilidad de las comparaciones y las metáforas con el fin de explicar y entender lo desconocido - en este caso un pueblo precolombino-, aunque otras observaciones pertinentes estarían dirigidas al hecho de que, en la segunda imagen atrás del embalaje, la princesa, vestida ahora de manera más sencilla, es "acompañada" por su perro, un xoloizcuintli, y por una llama. Respecto al perro, solamente cabe prevenir que entre los pueblos precolombinos se consumía la carne de cánido y, por ello, bien se podría dudar si la princesa paseaba a su mascota o a su almuerzo. ${ }^{27} \mathrm{~A}$ su vez, la presencia de la llama merece un enérgico comentario, ya que su aparición junto a la princesa tenochca es inconcebible. En el México antiguo no había llamas, es decir camélidos, y esta princesa, de haber existido, hubiera vivido en Tenochtitlán. En otros términos, ella pertenecía a la cultura dominante del actual territorio mexicano durante la Conquista, aunque, como se señaló, la muñeca Barbie Princesa del México antiguo se encuentra en Palenque, ciudad que, para el siglo Xvi, había sido devorada totalmente por la selva.

La mera concepción de una princesa tenochca acompañada por una llama en un contexto palencano muestra la progresiva anulación de las diferencias entre las culturas del México precolombino: la mixteca, la azteca, la maya y la teotihuacana y, en todo caso, esta insoslayable articulación no deja de suscitar serios problemas.

Los muchos comentarios originados por esta muñeca y la ambientación simbólica en la cual se desenvuelve son los elementos que finalmente la identifican como la Princesa del México antiguo al fincar sus nociones características e intentar situarla en un tiempo y un espacio determinados, en nuestro caso el México antiguo, y, partiendo de esta concepción, pese a la información histórica y cultural ambigua o errónea que presenta a la muñeca en su embalaje, Barbie se reconoce como una princesa del México antiguo, específicamente azteca o mexica. ${ }^{28}$ De esta forma, se vincula y representa a este pueblo histó-

27. No se puede descartar que los xoloizcuintli fueran mascotas; sabemos que los mayas los usaban como perros guardianes, como animales sacrificiales, a la vez que como alimento; se ha de considerar el simbolismo detrás de los cánidos en el México precolombino, por ejemplo, en prácticas funerarias. Véase Mary Pohl, "Maya Ritual Faunas: Vertebrate Remains from Burials, Caches, Caves and Cenotes in the Maya Lowlands", en Civilization in the Ancient Americas: Essays in Honor of Gordon R. Willey, I983, pp. 70-7I; Raúl Valadez, La domesticación animal, México, Universidad Nacional Autónoma de México-Instituto de Investigaciones Antropológicas, 2003, pp. 85-97.

28. Mattel indica que la muñeca está inspirada en la cultura azteca. Cabe señalar que azteca 
rico vía sus mujeres, a través de una mitología romántica creada y reformulada en fábulas articuladas en las viñetas escritas y en las escenas pintadas en el interior y el reverso de la caja que la confina.

\section{La "princesidad"}

La Barbie Princesa del México antiguo está dotada de los atributos que caracterizan y conforman a una princesa: es la hija del rey, lleva las mejores ropas $\mathrm{y}$ vive en un palacio real. Reúne las cualidades y calidades definitorias de la "princesidad" y, al verse ceñida en este marco, se inserta en una realidad que permite presentarla al mundo. ${ }^{29}$

La muñeca está constituida a partir de una memoria legendaria de los pueblos originarios de México y consagrada dentro del mito de las princesas de cuentos de hadas. De esta forma, sintetiza algunas características percibidas como aztecas, es decir mexicas, con aquéllas de la "princesidad" conforme a una imagen consolidada, a su vez, en el imaginario anglosajón de lo indígena. El resultado es la creación y presentación de una muñeca con un tema nativo americano subyugado a la noción de princesa. En otras palabras, Barbie encarna las realidades invisibles pertenecientes a un imaginario cultural a través de las cosas visibles, en las características materiales de una muñeca. Así, por medio de ella, una figura histórica ficticia se convierte en una muñeca temática.

y mexica son lo mismo; en el mundo académico anglosajón se emplea el nombre azteca más que el de mexica para nombrar a este pueblo. En el año "I Pedernal", este pueblo nahua parte de Aztlán, su lugar de origen, guiado por su dios tutelar Huitzilopochtli; pasa por Culhuacán, Chicomóztoc y Temoanchán. Más adelante, la captura y el sacrificio por extracción de corazón de los mimixcoa da lugar a que Huitzilopochtli les otorgue el nombre de mexicas. El sacrificio marcó su cambio de identidad, reflejado en su nuevo nombre. Federico Navarrete Linares, La migración de los mexicas, México, Consejo Nacional para la Cultura y las Artes, I998, p. 28. También véase Los origenes de los altépetl del valle de México, Universidad Nacional Autónoma de México-Instituto de Investigaciones Históricas, 201 I.

29. Rogers, op. cit., p. 54, sigue las propuestas de Patricia J. Williams, The Rooster's Egg, Cambridge, Harvard University Press, I995, al explicar que las muñecas negras e hispanas quedan culturalmente disociadas de los arquetipos románticos. Por mi parte, encuentro que en el caso de la Barbie Princesa del México antiguo y las otras princesas americanas sucede todo lo contrario. Insertar a la mujer nativa americana en el interior de los arquetipos románticos es lo que permite su mercadotecnia. En otras palabras, dado que han sido higienizadas y saneadas por la "princesidad", se hace posible introducirlas en el universo de Barbie, como lo crea Mattel, y presentarlas al mundo. 
La mujer azteca o mexica, al adquirir los atributos de la "princesidad", se edifica sobre idealizaciones propias del Occidente, rodeada de imágenes basadas en nociones medievales y renacentistas ligadas al linaje real, lo cual evidencia el continuo traslado al Nuevo Mundo de historias ficticias, fundadas en la realidad, "con hechizos y encantamientos", vinculados con relatos de una nobleza prehispánica. No queremos decir que en el México prehispánico no había princesas —en lengua náhuatl tlatocaciuapilli_, es decir, mujeres indígenas equiparables a las europeas, pertenecientes a lo que los habitantes del viejo continente concibieron como una realeza indígena. En este caso estamos ante las hijas de los pipiltin, las cuales contrastan con las de los maceualli, que eran los vasallos, la gente común. ${ }^{30}$

Al transitar por los cuentos de hadas para lograr ascender al trono que le concibió Mattel, el concepto de la Barbie Princesa del México antiguo comete varios errores y presenta muchos anacronismos —entendido este término como el acto de poner a una persona o cosa en un lugar o situación donde no pertenece; por ejemplo, información equívoca que desplaza a un personaje a un entorno históricamente incongruente. No obstante, en la concepción de esta muñeca, como en aquélla de otras pertenecientes a la colección, ${ }^{3 \mathrm{I}}$ a la vez que se repiten caracterizaciones de un pasado precolombino proveniente de diversas regiones y tiempos, se reúnen y rehabilitan fragmentos de este pasado; se crean e implantan nuevos personajes. En este caso una princesa del México antiguo, y ella, precisamente por verse conformada por una mitología clásica e incorporada a las idealizaciones románticas, al identificarse con los ideales y fantasías de la cultura occidental, fácilmente integra a una mujer indígena de un remoto pasado que ahora resulta familiar, razón por la cual se impone y logra trascender en el imaginario popular.

30. Alonso de Molina, Vocabulario de lengua castellana a mexicana y mexicana a castellana, México, Porrúa, 1977; Remi Siméon, Diccionario de la lengua náhuatl o mexicana, México, Siglo XXI, I988.

3I. Rogers, op. cit., p. 54, comenta que las muńecas Barbie India, Oriente y Nativa Americana de la colección Muñecas del Mundo muestran también muchas generalizaciones y errores. Y si uno revisa los comentarios de los clientes acerca de las muñecas étnicas/internacionales, por ejemplo, en www.amazon.barbie.collector, encuentra que los consumidores están conscientes de ello y no les parece lo más relevante; quizá sea así porque la fantasía de Barbie logra encubrir y velar cualquier falta de veracidad o realidad histórica. 


\section{Otras princesas americanas}

La Barbie Princesa del México antiguo no se encuentra sola en su obtención de una tiara. La colección Barbie Princesa, Muñecas del Mundo fue concebida en 200I. Las primeras muñecas de esta colección pertenecen a regiones y países de Europa y Asia que tradicionalmente han tenido monarquías y princesas. A ellas se suman las princesas de África y de América; en todo caso, son muñecas que, al decir de Mattel, representan "culturas de la historia mundial, que toda niña debe agregar a su colección Muñecas del Mundo, colección Princesa Barbie". ${ }^{2}$

Los personajes que ha encarnado Barbie evidencian la génesis de las actitudes y nociones de sus fabricantes dirigidas hacia los antiguos y los actuales habitantes indígenas - pueblos tradicionales - de muchas latitudes del mundo, en este caso determinados países del continente americano. Por ejemplo, las muñecas Barbie Princesa Inca y Barbie Princesa Navajo, así como la Barbie Princesa del México antiguo, son una muestra de la búsqueda del fabricante de juguetes por lograr integración social a la luz de su interés por ampliar su base de consumidores.

La Princesa Inca encuentra sus precursoras directas en un par de muñecas Barbie que representan a Perú. La más temprana, de 1986, viste un "traje peruano auténtico"; 33 y la segunda edición Barbie del Perú, de 1999, ${ }^{34}$ igualmente se describe como vestida de manera auténtica, para reflejar la cultura de ese país, al decir de su publicidad. En cuanto a la Barbie Princesa de los Incas de 200I, "inspirada en la dinastía real de una edad exótica [...] lleva un vestido de tafetán color azul profundo con un colorido borde decorado, que retoma los modelos de textiles incas auténticos". Y debido a que es una "princesa divina" y como los reyes y reinas era descendiente de Inti, el poderoso dios del Sol, también lleva "muchas piezas de joyería de oro deslumbrante", "símbolo de Inti y un metal precioso, que era propiedad sólo de la realeza".35

Por su parte, la Princesa Navajo, princesa de "una cultura pacífica de indios nativos americanos, cuyas raíces subyacen en antiguas tradiciones de respe-

32. Princess of Ancient Mexico ${ }^{\mathrm{TM}}$ Barbie, 2004, Collection Dolls of the World-The Princess Collection, Product Code: C2203.

33. Peruvian Barbie, 1986, Dolls of the World-South America, Product Code: 02995.

34. Peruvian Barbie, 1999, Dolls of the World-South America, Product Code: 21506.

35. Princess of the Incas Barbie, 200I, Dolls of the World-The Princess Collection, Product Code: 28373 . 
to a la tierra y la naturaleza, así como en un potente patrimonio espiritual", ${ }^{36}$ también encuentra sus antecedentes en la colección Muñecas del Mundo, tal como es singularizada por la Barbie Nativa Americana en sus cuatro ediciones. Aunque el estudio de las muñecas Barbie correspondientes a las culturas indígenas de Norteamérica es un asunto más complejo que el caso peruano, pues Mattel ha concebido numerosas muñecas representantes de pueblos nativos de América del Norte.

A estas concepciones se las ha desacreditado por estimar que homogeneizan a los grupos de indios americanos al grado de no poder distinguirse entre ellos; aunque es necesario matizar, pues los nombres y las viñetas de algunos ejemplos permiten diferenciar al menos entre unos grupos que poblaron las llanuras y otros la costa noroeste. ${ }^{37}$

Algunas caracterizaciones de la Barbie Esquimal parecen responder a críticas de esta naturaleza. En las dos primeras ediciones viste un atuendo apropiado para "las temperaturas gélidas del Ártico", pero en la última, ahora perteneciente a la colección Más Muñecas de las Culturas del Mundo, ya no lleva un traje tradicional "esquimal". Mattel la presenta vistiendo un hermoso traje de gamuza blanca, cuando personifica a la leyenda inuit, de tal modo que una cultura se ve reconocida y reivindicada por Barbie como su representante. ${ }^{38}$

\section{Lo auténtico}

La Barbie Princesa del México antiguo, la Barbie Princesa Inca y la Barbie Princesa Navajo se crearon principalmente como un medio para vender más

36. Princess of the Navajo Barbie, 2004, Dolls of the World-The Princess Collection, Product Code: B8956.

37. Rogers, op. cit., pp. 54-55. Véase, por ejemplo, Native American Barbie, Dolls of the World-North America, 4 ediciones, Product Code: oI753, II609, I2699, I8558. No obstante, destaca que la primera princesa de la colección de muñecas en representar a los nativos de América del Norte pertenece a los navajo — un pueblo "pacífico" y sedentario, opuesto a los apache, por ejemplo, considerado como pueblo "guerrero" y nómada.

38. Inuit y esquimal son dos términos empleados para denominar a varios grupos culturales que habitan las regiones árticas de América, Groenlandia y Siberia. La palabra esquimal ha caído en desuso en Canadá por ser considerada peyorativa y oficialmente sólo se utiliza inuit. No obstante, en regiones de los Estados Unidos, Alaska y Siberia el nombre esquimal sigue en uso. Inuit Legend, 2005, More World Culture Dolls, Product Code: G8892. Véase también Eskimo Barbie, Dolls of the World-North America, Product Code: 03898 y 09844. 
muñecas; son producto de un concepto de mercadotecnia premeditado y cuidadosamente diseńado que promulga su "autenticidad". Por ello, el problema de lo auténtico ha de considerarse aquí al menos someramente, pues las muñecas internacionales Barbie y otras de calidad más "tradicional" y "genuina", como las muñecas Kachina de los hopi, analizadas por Leah Dilworth en su estudio, ${ }^{39}$ o una muñeca de trapo navajo adquirida en una reservación india hace 40 años en Nuevo México, no son tan diferentes.

Como la muñeca Kachina y la muñeca navajo, Barbie es tanto un juguete como un objeto mítico. Sirve para domesticar y presentar al "otro/a" cuando se incorpora a la vida de un niño. ${ }^{40}$ Ciertamente, la Barbie Princesa Navajo es un producto mucho más comercial, una mercancía concebida y producida en masa en Indonesia por una compañía transnacional, pero ¿es acaso menos auténtica que la muñeca tradicional?

Las muñecas Barbie son "versiones actualizadas" e "inspiradas en”, pero los ejemplos, ciertamente menos industriales, más "nativos", revelan condiciones semejantes. Como la muñeca de plástico vinílico, la Kachina y la navajo fueron fabricadas para proveer al turismo de un recuerdo. ${ }^{4 \mathrm{I}}$ En la actualidad, incluso las dos muñecas "tradicionales" se venden en la tienda de obsequios del museo Smithsonian en Washington; a su vez, la Barbie Princesa Navajo se adquiere en tiendas departamentales de Nuevo México. Son objetos creados ex

39. Las muñecas Kachina son representaciones de seres sagrados entre los indios pueblo. Leah Dilworth, "'Handmade by an American Indian'. Souvenirs and the Cultural Economy of Southwestern Tourism”, en Hal K. Rothman (ed.), The Culture of Tourism. The Tourism of Culture. Selling the Past to the Present in the American Southwest, Alburquerque, University of New Mexico Press, 2003, pp. IOI-I I7, véase p. I06. La estudiosa indica que los objetos fabricados para el turismo requieren simplificación y producción en serie; en todo caso, no sucede una cosa distinta en la fabricación de las Barbie Princesas del Mundo. Véase también Marcus Banks, "True to Life: Authenticity and the Photographic Image, Debating Authenticity. Concepts of Modernity", en Thomas Fillitz y A. Jamie Saris (eds.), Anthropological Perspective, Óxford/Nueva York, Berghahn Books, cap. 9, 2013.

40. Dilworth, op. cit., p. I04; Lord, op. cit., p. 76, escribe: "Tradicionalmente los padres hopi le dan a sus hijos figuras Kachina — objetos de culto que representan deidades - con qué jugar en ocasiones ceremoniales. Estas muñecas les enseñan los detalles de sus creencias. Barbie, como la muñeca Kachina es juguete y objeto mítico — mujer moderna y mujer Ursin ombligo, sin madre, una encarnación de la 'Diosa de los mil nombres". Agrega: "En la represa de la memoria comunal [...] el inconsciente colectivo [...], Barbie es un arquetipo de algo antiguo, matriarcal y profundo".

4I. Lord, op. cit., p. I77; Dilworth, op. cit., pp. I03-I04. 
profeso para suplir las demandas particulares de un mercado igualmente internacional, "global".

Sería imposible decir que todas las concepciones de las muñecas de la colección Muñecas del Mundo son auténticas, como lo sería afirmar su veracidad histórico-cultural, pues no siempre aciertan en la representación de una u otra cultura. Como se comprobó, pese a los argumentos en contra de los directivos de Mattel, la concepción de la Barbie Princesa del México antiguo incurre en varios errores. Un hecho permite cuestionar las técnicas de investigación de sus creadores: según esta compañía, en la concepción de las muñecas se busca "garantizar la autenticidad dentro de la fantasía que se esfuerzan por promover", ${ }^{2}$ y llega a divulgar que los diseńadores y creadores de muñecas representantes de algún país o grupo étnico son de esa nación, grupo o raza: por ejemplo, las últimas series de Barbies negras, emitidas en 2009, fueron concebidas y diseñadas por una mujer afroamericana. ${ }^{43}$

Debido a lo anterior cabe preguntarse en qué medida aportaría, o no, a su validez y autenticidad que alguna muñeca — como la Barbie Princesa Navajo o la Barbie Princesa Azteca - fuese diseñada por una nativa americana. En otras palabras, ¿̨la autenticidad de la muńeca depende del lugar donde se adquirió, de quién la fabricó o de la intención detrás de su factura?

\section{Retratos de mexicanas}

En cuanto a la génesis de la Barbie Princesa del México antiguo, parecería que el concepto e interés por México comenzó tempranamente entre los creadores de Barbie. ${ }^{44}$ Muy pronto, después de que se comercializó Barbie (1959), ya pa-

42. Lord, op. cit., p. I77; "Doll Power: Barbie Celebrates 5oth Anniversary and World Toy Dominance", http://www.telegraph.co.uk/news/worldnews/northamerica/usa/40I4779/ Doll-power-Barbie-celebrates-5oth-anniversary-and-toy-world-dominance.html; consultado el 29 de diciembre de 2008.

43. La Black Barbie de 1980 es una creación de Kitty Black Perkins. "Mattel Introduces Black Barbies, Gets Mixed Reviews", http://www.foxnews.com/printer_friendly_ story/0,3566,562706,00.html; consultado el 9 de octubre de 2009. También Lord, op. cit., pp. I08 y I74-176, menciona que, como en la concepción de la muńeca Barbie Malasia participaron los trabajadores de la fábrica Mattel en dicho país, ha recibido aprobación en cuanto a su autenticidad y atractivo.

44. En 1967 Mattel abrió la primera fábrica en Mexicali, México, para producir la muñeca Barbie, y en 1970 la segunda. Lord, op. cit., pp. 59 y 92. 
ra 1964 se vendía, por separado, un traje de señorita mexicana completo para vestir a la muńeca. ${ }^{45} \mathrm{Y}$ su novio Ken, con quien Barbie sostuvo una relación intermitente a lo largo de varios años, la acompañaba en esa ocasión vestido con su traje de mexicano. "Con su sombrero de ala [...] ¡era el 'gringo' más guapo de la ciudad!", rezaba la publicidad del momento. ${ }^{46}$

Los trajes mexicanos "él y ella" venían acompañados por un panfleto de viaje impreso a todo color, y su propósito, me imagino, era ofrecer a quien los comprara la posibilidad de ir a lugares exóticos, al jugar, plasmando su función lúdica con las expectativas y alucinaciones creadas por la noción de viajar a países lejanos. Los trajes y el folleto dan la pauta y exteriorizan las posibilidades para el recreo, que se pueden realizar con la muñeca, situando a Barbie y a Ken como viajeros mundanos, dispuestos a tomar el mundo, vestidos con las ropas consideradas por sus creadores como "tradicionales" de una u otra región, como es el caso de México.

El gusto de Barbie por tomar formas siempre cambiantes es un asunto que evidencia cómo Mattel, al vestirla con determinadas ropas, crea y perpetúa imágenes tipificadas y estereotipadas. ${ }^{47} \mathrm{Al}$ ponerse este traje de señorita, Barbie se viste y se disfraza como mexicana, en contraste con lo que sucede en los siguientes ejemplos, en los cuales la muñeca se comercializa y vende engalanada en un traje tradicional de mexicana. En el primer caso, el traje la viste como mexicana, mientras que en los ejemplos siguientes Barbie es mexicana cuando adopta la vestimenta y otros rasgos característicos. Distinguir entre ambas concepciones permite subrayar el delicado camino que se emprende en la factura de imágenes de determinado grupo o raza al intentar caracterizarlos. ${ }^{48}$

Quienes más se han referido al fenómeno Barbie han señalado que es un ser amorfo, en el cual se depositan varias capas de significados; los más mencionados son los vinculados con modelos de imagen corporal y temas de género. Y si

45. Barbie in Mexico \#0820, 1964, 800 Series Fashions, Product Code: 0820.

46. Ken in Mexico \#0778, 1964, 700 Series Fashions, Product Code: 0778.

47. Rogers, op. cit., pp. 53-54; Lord, op. cit., pp. 176-177.

48. Deborah Poole, "An Image of 'Our Indian': Type Photographs and Racial Sentiments in Oaxaca, 1920-1940", Hispanic American Historical Review, Duke University Press, 2004, vol. 84, núm. I, pp. 37-82. A lo largo de su estudio, Poole determina que el traje típico nacional o traje regional proclama la identidad local y acentúa los atributos característicos de una cultura, raza o nación; asimismo, puede ser tomado como un estereotipo conformado desde el interior de la comunidad que crea su propio traje. También véase Deborah Poole, Vision, Race, and Modernity, Nueva Jersey, Princeton University Press, 1997, cap. 4. 
se considera la diversidad de mujeres y nacionalidades que ha representado esta muñeca por medio de los atributos de su vestimenta, su realización igualmente abarca otras cuestiones, como las de identidad, cuando no solamente tipifica sino otorga carácter físico a un pueblo o incluso a una nación. El carácter de un grupo se transmite por medio de su representación encarnada por Barbie porque la muñeca no solamente copia aspectos de una identidad, indumentaria y costumbres, sino que la efectúa, y, de tal modo, es una imagen que encarna en sí misma más que un mero artificio simulador; es una identidad, al incorporar los elementos característicos de determinado grupo. En otras palabras, al asemejarse al sujeto que representa, es también el sujeto que reproduce.

\section{Ser o parecer mexicana}

En un ejemplo temprano de Barbie Mexicana, una edición de I989, su traje "refleja la fuerte influencia española que prevalece en su país", al decir de Mattel, mientras que en el segundo, presentado siete años más tarde, la muńeca luce "un traje de fiesta en rojo, blanco y verde para celebrar los colores de la bandera de México".49

Si bien Barbie tiene poca credibilidad como negra, asiática, nativa americana, indígena o incluso hispana, por ser finalmente una muñeca que se identifica como blanca, ${ }^{50}$ como mujer mexicana, tampoco es factible. En estos dos ejemplos, el rostro de la muñeca ya no es precisamente el de Barbie: su piel es más oscura, su cabello negro y, curiosamente, sus ojos más grandes y rasgados. En todo caso, siempre es Barbie pero su cara es ahora otra. ${ }^{51}$ Además de llevar las ropas de otro pueblo, se produce con la cara de una mexicana al adoptar facciones características o estereotipadas, a manera de una máscara perfi-

49. Mexican Barbie, Ist Edition, 1989, Special Edition. Dolls of the World-North America, Product Code: o1917; Mexican Barbie, 2nd Edition, 1996, Collector Edition Dolls of the World-North America, Product Code: I4449.

50. Rogers, op. cit., pp. 47-55; Lord, op. cit., p. I08; Augustyniak, "Hispanic Barbie...", op. cit., pp. 40-43. Cabe mencionar que este último autor también publicó Barbie Doll Around the World 1964-2007, Paducah, Collector Books, 2008, un libro informativo en el cual, al decir de las reseñas, aborda el tema de las muñecas Barbie en el mercado extranjero. Hasta el momento no he tenido acceso a esta publicación.

5I. Barbie es mutable y ha trascendido; aunque sus ojos cambien de color tan rápido como su pelo y sin importar qué raza o identidad adopte, en toda circunstancia se le identifica como blanca. Rogers, op. cit., pp. 47-48. 
lada para representar un papel, que cambia según las necesidades de Mattel. El cuerpo es siempre el mismo, pero "no es sólo una cara bonita... ¡Tiene I I rostros diferentes, cada uno con distinto tono de piel!" 52

Cuando Barbie está vestida y tiene el rostro de determinada etnia, sumado a la mercadotecnia que rodea el embalaje y la publicidad de cada muńeca, es la encarnación de ese grupo ante el mundo, de tal modo que lo personifica: ya no es Barbie vestida como, sino Barbie siendo, en este caso, mexicana. No simula el papel de, ni actúa como, Barbie es mexicana. Barbie es México. En la edición de 20I2, a la muñeca ya no se le presenta como la Barbie Mexicana (Mexican Barbie) sino como Mexico Barbie Doll. Ahora, "inspirada en los tradicionales mariachis y marimbas está lista para cualquier fiesta”. Engalanada con un vestido de holanes de color rosa, con encaje y listones, carga su pequeño perro chihuahueño en brazos. .3

Las muñecas Barbie muestran rostros ajenos y visten trajes híbridos que conjugan elementos que, aunque no son totalmente erróneos, constituyen retratos de caracterizaciones tipificadas de la mujer mexicana; lo anterior se ve concretado en la muñeca Barbie Cinco de Mayo, editada en 2007. Conmemora la victoria, en I862, de los soldados mexicanos sobre el ejército francés en la batalla de Puebla con "diversión, fiestas, coloridos desfiles, música alegre y deliciosa comida", con "un vestido en holanes inspirado en los auténticos trajes mexicanos". 54

Se exaltan en este ejemplo y otros de la misma colección las fiestas tradicionales pertenecientes a algunos países representados por Barbie en la co-

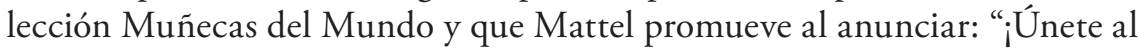
Festival! ¿Qué mejor manera para celebrar la fascinante diversidad de nuestro mundo que con Barbie, vistiendo el tradicional atuendo festivo? Ella capta la belleza de cada cultura en un llamativo estilo auténtico." Son prueba del deseo del fabricante de juguetes por proporcionar a las nińas de todas las etnias y culturas otra forma de jugar con Barbie en su búsqueda por "conectarse con el mundo [ïuna mujer global?] y mostrarle que representa

52. Adriana Gregorio, "Belleza de muñeca", Reforma, 7 de marzo de 2009, sección "Gente chiquita", p. 5 .

53. Mexico Barbie Doll, 2012, Dolls of the World-North America, Product Code: W3374. Me atrevo a decir rosa mexicano (usado por Tamayo en sus lienzos o por Barragán en sus casas), y el origen mexicano del perro chihuahueño debe ser subrayado.

54. Cinco de Mayo Barbie Doll, 2007, Collection Dolls of the World-Festivals of the World, Product Code: K792I. 
diferentes nacionalidades y grupos étnicos, mientras que adopta sus rasgos y característicos trajes".55

Si bien esta muñeca representa una de las festividades contemporáneas que "las personas de todos los Estados Unidos y México celebran por la libertad y la cultura de México, y que conmemora una de las festividades tradicionales mexicanas más célebres en los Estados Unidos", ${ }^{6}$ como afirma Mattel en las rúbricas que la presentan, la Barbie Princesa del México antiguo retrata algo muy diferente: las ancestrales prácticas e imágenes, remitidas a la actualidad y adecuadas al conocimiento popular por medio de su inserción en un esquema de cuentos de hadas. Es muestra de cómo fragmentos de imágenes codificadas — poseedores de determinado significado e importancia-, una vez traducidos e insertados por el pensamiento de los creadores de la muñeca para adaptarse e incorporarse a nociones de mercadotecnia — consideradas también colonialistas_, 57 perdieron su significado original y produjeron una nueva articulación que modeló la imagen de un país y de su gente, así como las expectativas y las experiencias ligadas con ellos en un tránsito globalizador.

Una identidad nacional mexicana forjada por Mattel a lo largo de los ańos, al retomar y transformar ideas que se han desarrollado acerca de las mujeres mexicanas y de sus festividades, descansa sobre los hombros de la muñeca. Y el estudio de la Barbie Princesa del México antiguo y de las ediciones de Barbie Mexicana permite mostrar cómo se crean y transmiten imágenes mentales, fundadas en la realidad adecuada por la fantasía, en imágenes físicas, pictóricas y literalmente plásticas, en el marco de los intercambios culturales que continúan y se derraman ahora por los medios mercantiles masivos..$^{58}$

55. http://www.barbiecollector.com/dolls-world-festivals-world

56. Cinco de Mayo Barbie Doll, 2007, Collection Dolls of the World-Festivals of the World, Product Code: K792I.

57. Lord, op. cit., p. I95.

58. Stuart Hall, "Old and New Identities, Old and New Ethnicities", en Anthony D. King (ed.), Culture, Globalization and the World-System. Contemporary Conditions for the Representation of Identity, University of Minnesota, I997, pp. 4I-68. 


\section{Una muñeca fea}

No tiene mucho sentido juzgar si las muñecas Barbie son correctas o incorrectas, exactas o no, útiles o no. Parto de la premisa de que, como cualquier otro juguete, Barbie es ambivalente: según su contexto, puede ser tomada como buena o mala. Aunque los aspectos negativos siempre han sido los más referidos, quizá por costumbre o a manera de rechazo a todo lo que implica la cultura popular norteamericana y su irreductibilidad.

Por lo general, no son las características positivas de esta muñeca las que se resaltan, aunque sí las tiene, particularmente la colección Barbie del Mundo. Sensiblemente, su creación, y la de su rama - la colección Princesas del Mundo-, ha logrado dar a conocer las culturas y naciones del planeta, y determinados aspectos de las costumbres de sus mujeres han sido exaltados. En primer lugar, a nosotros los mexicanos, quienes de manera más inmediata nos hemos visto condicionados por la cultura popular estadounidense y por un mercado internacional, a partir de la inserción de la muñeca en una red transnacional de comercialización y distribución. ${ }^{59}$

Las muñecas Barbie se venden en más de I50 países; y en Francia, España, Italia y Alemania, Barbie es la número uno en ventas de muñecas. En Puerto Rico, 72 por ciento de las niñas tienen Barbies, y en otros países de América Latina este fenómeno se repite: 49 por ciento de las niñas en Chile tienen Barbies y 37 por ciento de las niñas en Venezuela y en Argentina poseen igualmente una o más de estas muñecas. ${ }^{60}$ Para México los datos no estaban disponibles, pero la apertura de la primera Barbie Boutique en Santa Fe, en la ciudad de México, es ejemplo del éxito de la muñeca en la capital del país, como lo son también los grandes espectaculares sembrados a lo largo del Anillo Periférico que anuncian una Barbie rosa.

59. Arabia Saudita y Siria, así como otros países musulmanes, se deben excluir, pues tienen una muñeca equivalente llamada Fulla, que lleva atuendos más apropiados y menos reveladores. En Japón y China las muñecas Barbie también están siempre presentes, y se venden muchas diariamente.

6o. "Doll Power: Barbie Celebrates 5oth Anniversary and Toy World Dominance", The Telegraph, 29 de diciembre de 2008; Susan Taylor Martin, "The Doll that has EverythingAlmost"; St. Petersburg Times, http://www.stimes.com/2005/05/I5/, Floridian/The-doll-thathas-eve.shtml; consultado el Is de mayo de 2005; Lord, op. cit., p. 300; Weissmann, op. cit., p. 88 . 
¿Qué consecuencias conlleva esta distribución masiva? Barbie no es sólo la imagen corpórea plástica de determinado pueblo o país; es la imagen exteriorizada del grupo que representa, que transita por el mundo entero en una multiplicidad de medios impresos, sobre todo cibernéticos; sencillamente véase www.barbie.com y la variedad de idiomas en que se reproduce esta página.

Aunque en una forma carente de autenticidad, con rasgos y aditamentos tipificados y repitiendo muchos clisés característicos de la vestimenta, las peculiaridades y el entorno de las culturas que Barbie representa son construcciones y reconfiguraciones de las mujeres de distintas partes del mundo. Son convocadas y representadas inmersas en el interior de un marco occidental — princesidad_-, que las valida y permite tomar a determinado grupo étnico y presentarlo a los ojos del mundo. Son transportadas en un medio mutable y cambiante como el "plástico""ri e insertadas en un mercado masivo de consumidores al presentarlas como princesas para repetir nociones preconcebidas e ideas erróneas generalmente vinculadas a países no occidentales, reformulando entonces nuevas asociaciones.

La información que promueven las muñecas de la colección Princesas del Mundo incorpora nuevas palabras y frases acerca de fiestas y festejos, nombres de árboles y edificios, así como conceptos de belleza y hábitos culinarios de diferentes pueblos, y se puede concebir como una estrategia de Mattel para ampliar los horizontes de quienes consumen sus muñecas. En este tenor, pensemos que al obtener una nueva Barbie una niña diría:

“iMira, tengo una Barbie negra!”, y al sonido de las trompetas y los xilófonos, la gran fiesta multicultural se iniciará con Barbie. Si acaso los padres no fueran tan 'globales' y temieran la xenofobia, Barbie les daría alivio: ¡la colección de versiones étnicas llevará a los espíritus jóvenes hacia la apertura y la tolerancia! ${ }^{62}$

A pesar de que aparentemente las caracterizaciones y las generalizaciones se repiten, las muñecas de la colección Princesas del Mundo logran exponer a niños y coleccionistas diferentes nacionalidades, grupos raciales, países y latitudes, lo cual se podría considerar "conocimiento étnico". ${ }^{63}$ Pese a los errores

6r. Roland Barthes, Mythologies, Nueva York, Hill and Wang, 1982, pp. 97-99.

62. Marie-Françoise Hanquez-Maincent, "L'abécédaire de Barbie", Le dossier: Glisse urbaine. L'esprit roller: liberté, apesanteur, tolérance, Mutations, núm. 205, junio de 200I, pp. 25 I-260, véase especialmente la p. 259.

63. Este término (en inglés "ethnic knowledge") fue tomado de Dilworth, op. cit., p. I04. 
en que puede incurrir la información histórica y cultural —al decir de algunos consumidores-, la muñeca puede llegar a inculcar cierto conocimiento: consideremos que para una coleccionista "la Barbie azteca es otra maravillosa manera para aprender historia" y, al obtenerla, "uno tiene la sensación de estar adquiriendo un pedazo de la historia". ${ }^{64}$

Estamos lejos de poder afirmar la existencia de veracidad detrás de la concepción de las muñecas que representan a las mujeres del mundo y ciertamente nuestra Princesa Azteca lleva a cuestionar en gran medida las técnicas de investigación de Mattel; no obstante aquí no perseguimos tal propósito. He preferido presentar estas muñecas a manera de nuevas alegorías que repiten muchas características de los prototipos y representaciones de los habitantes del continente americano y de otras regiones. Mis construcciones actuales repiten de manera orgánica muchas construcciones anteriores y caracterizaciones tempranas de las representaciones formuladas de las primeras alegorías de las partes del mundo, en las cuales los continentes y sus habitantes están figurados y encarnados por las mujeres vestidas en trajes y llevando accesorios que las designan. Por ejemplo, el primer atlas del mundo: en el frontispicio del Teatro del Mundo de Abraham Ortelius, de $1564,{ }^{65}$ ninguna nacionalidad o país en particular está representada; sí lo están los continentes: Europa, Asia, África y América, cada uno personificado y encarnado por una mujer que reúne determinadas particularidades culturales, es decir, una serie de atributos propios de la región que representa y de sus habitantes (fig. I) ${ }^{66}$

64. "Customer reviews", Dolls of the World: Princess of Navajo Barbie, amazon.com, consultado el I 4 de julio de 2004 .

65. Theatrum Orbis Terrarum, en Couleurs de la Terre. Des mappemondes medievales aux images satellitales, Monique Pelletier (dir.), París, Seuil, Bibliothèque Nationale de France, 1998, pp. 74-75. Hugh Honour, The New Golden Land. European Images of America from the Discoveries to the Present Time, Londres, Fleming Honour, I975, pp. 84-I I7, propone que las tempranas encarnaciones de los continentes por parte de mujeres surgen en el Renacimiento en el contexto de las obras de teatro. Se considera que están ligadas a las representaciones de las alegorías de los continentes concebidas por Ortelius.

66. Las alegorías de los cuatro continentes fueron sistematizadas y publicadas en la Iconología de Cesare Ripa en I593: Europa se encuentra asociada a un caballo, lleva una corona en la cabeza, carga una cornucopia o yace sentada junto a un globo terráqueo; África lleva un tocado de flamas en forma de fuego, en la mano carga una rama de bálsamo y se encuentra junto a un elefante; Asia se figura ligada a un camélido, carga en las manos un incensario y viste de sedas, y a América generalmente se la asocia con un lagarto: carga un arco y una flecha y lleva una cabeza cercenada en las manos. A su lado reconocemos a la personificación de la Tierra del Fuego como indica la pequeña flama debajo de su busto, y que en el siglo Xvi se 


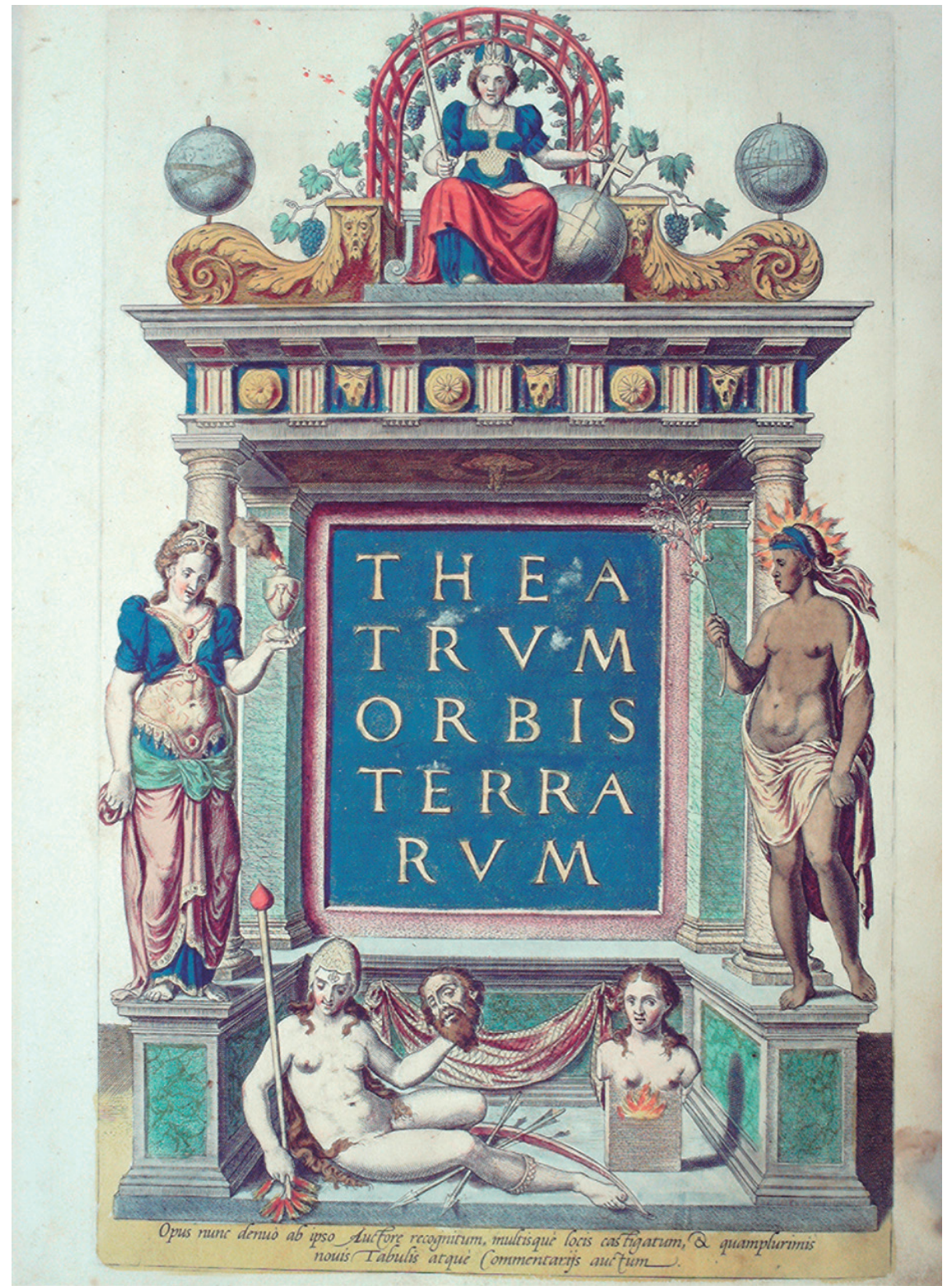

I. Abraham Ortelius, frontispicio de Theatrum Orbis Terrarum, I564. Universitätsbibliothek Freiburg/BR/Historische Sammlungen Rara, J8540a. 


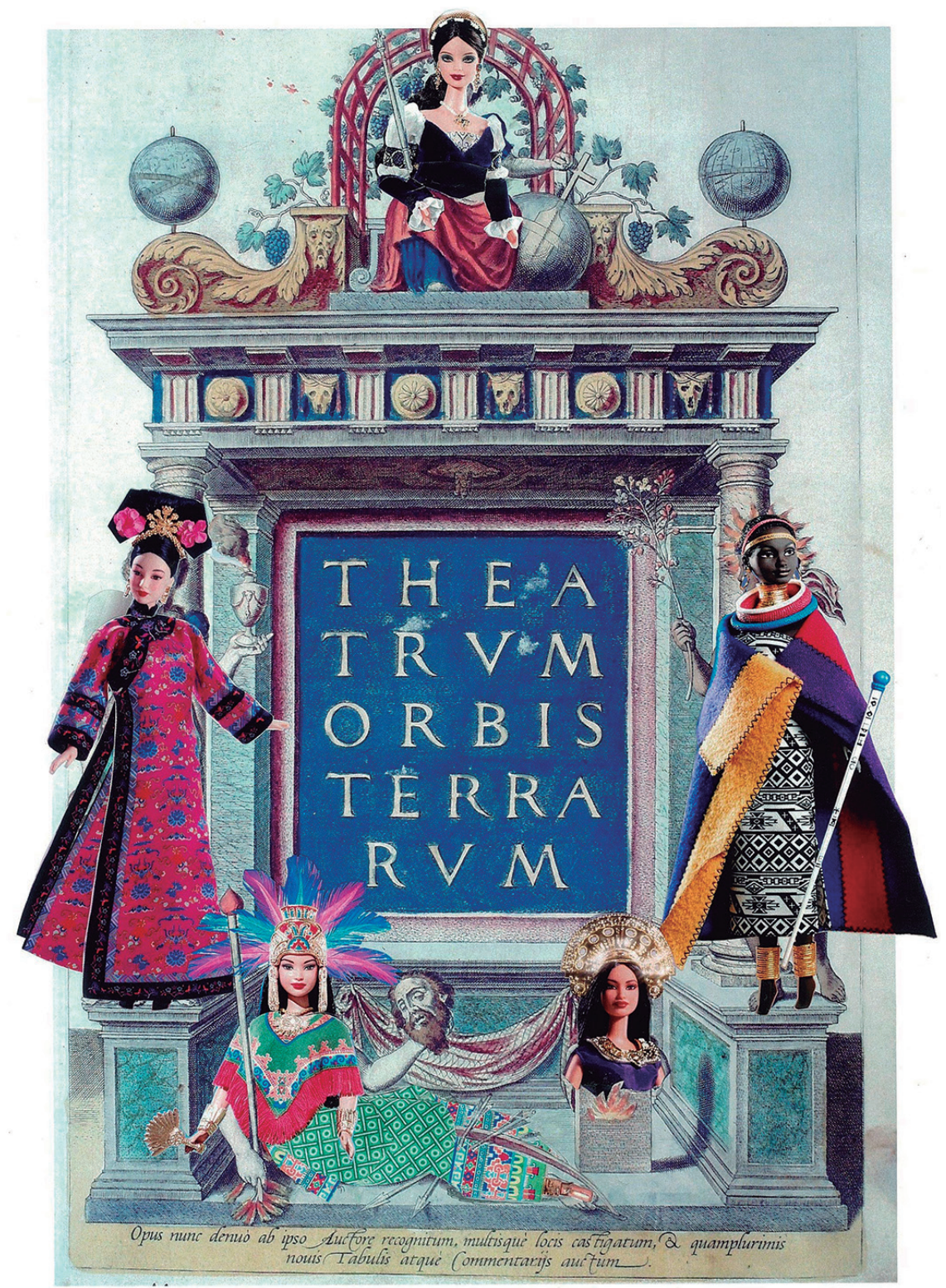

2. Emilie Carreón Blaine, Frontispicio del Teatro del Mundo de Abraham Ortelius con princesas del mundo personificando a los continentes, collage, 2013. 
Algo semejante sucede con las muñecas Princesas Barbie. Una reconfiguración de la concepción del frontispicio de Ortelius, pero situando a una princesa Barbie de cuatro países diferentes como alegoría de cada continente, es necesaria para mostrar lo anterior. La reproducción que aquí se presenta, en la cual la elección de las princesas puede ser arbitraria - la princesa de Sudáfrica representaría a África, la Princesa Azteca a América, la Princesa China a Asia y la Princesa del Renacimiento a la hoy difícil encarnación de Europa (fig. 2) - , pretende ejemplificar en muy diferentes tiempos cómo la repetición de las concepciones que buscan insertar "al otro" continúa a través de los procesos de pensamiento convencional y las concepciones particulares de cada época. En las antiguas alegorías concebidas por Ortelius en el siglo XVI y en las de Mattel propias de los siglos xx y xxI, ${ }^{67}$ las representaciones de cada región, país o pueblo siguen parámetros constantes y repiten determinados patrones y modelos. Así, los dos frontispicios se asemejan en la medida en que en ambos encontramos nociones preconcebidas que se repiten durante los siglos, en las cuales las características definitorias de las mujeres de diferentes culturas se mezclan y reorganizan en nuevas configuraciones sin reflejar necesariamente la verdad, es decir, los datos históricos y arqueológicos registrados. Son, en cada caso, alucinaciones que reflejan la producción y la recepción de antiguas imágenes hoy de viaje por las redes y los medios masivos de comunicación de la modernidad. \$s

tenía como un pequeño continente. Cada una de las alegorías presenta un animal que habita en la región y, por tanto, la personifica; estos animales emblemáticos no están muy distantes de los que acompañan a la Barbie Princesa Azteca y la México Barbie $3^{\text {a }}$ edición: xoloizcuintli y chihuahueño.

67. Véanse, por ejemplo, las cuatro Bob Macckie Fantasy Goddess: la de Asia (Product Code: 20648), la de África (Product Code: 22044), la de América (Product Code: 25859) y la del Ártico (Product Code: 50840), pertenecientes a la colección Belleza Internacional de Barbie. www.barbiecollector.com/shop/doll/fantasy-goddess.

* Artículo recibido el 25 de junio de 2012 ; aceptado el 5 de noviembre de 2012. 